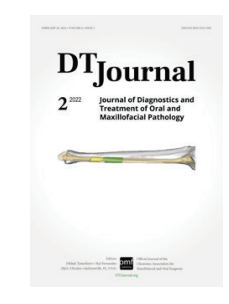

\title{
Anniversary Time in a Rapidly Evolving and Complex Landscape
}

\author{
Evangelos G. Kilipiris
}

Every day physicians fight against diseases for the universal desire for a better, disease-free life. Potent weapons to achieve this include the constant attainment of knowledge and skills. A strategic plan and a prerequisite to reaching this goal is the existence of a community of dedicated medical scientists who can study, work, think, communicate and write.

In this environment, the Journal of Diagnostics and Treatment of Oral and Maxillofacial Pathology (which is also called DT Journal because of the domain name www.dtjournal.org) was born to provide a medium for this communication to catalyze new ideas and incidentally also to assure a permanent repository of scientific information.

Today, DT Journal is proud to celebrate an important milestone: the Fifth Anniversary. A journal that was created to unify the world of oral and maxillofacial surgery (OMS) and share oral and maxillofacial surgical knowledge as broadly as possible, without any borders or barriers. A journal committed to advancing scientific knowledge about OMS across the globe while also addressing the most pressing issues facing oral and maxillofacial surgeons in the 21 st century.

During these years, the DT Journal has offered

MD, DMD; Director, Journal Development Department, Journal of Diagnostics and Treatment of Oral and Maxillofacial Pathology (JDTOMP), Bratislava, Slovak Republic.

Corresponding author's address: National Institute of Children's Diseases and Faculty of Medicine at Comenius University, 1 Limbova Street, Bratislava 83340, Slovak Republic.

E-mail: varonos@live.co.uk its readers up-to-date original research articles and scientific and educational review articles from virtually every corner of the OMS field. It has consistently covered scientific domains that range from oral surgery and implantology to microvascular reconstructive surgery and complex craniofacial reconstruction.

On this Anniversary, we owe gratitude to the pioneers who were instrumental in turning the journal's launch into an instantaneous success. A truly global work took place in 24/7 operation with editors, editorial board members, reviewers, contributors, and readers on all continents. And the strength of the current DT Journal editorial team derives mainly from this diverse and international composition and the strong support from its international professional affiliates, which distinguish it from other leading OMS journals.

At this moment, I would like to recognize the tremendous work of our Editor in Chief -Oleksii Tymofieiev, Deputy Editor in Chief - Rui Fernandes, and Managing Editor - Ievgen Fesenko. Their calm demeanor, competence, and determination set a collaborative tone among the whole team.

Anniversaries remind us of important events.

Please cite this article as: Kilipiris EG. Anniversary time in a rapidly evolving and complex landscape. J Diagn Treat Oral Maxillofac Pathol 2022;6(2):26-9.

Available online 12 February 2022

https://doi.org/10.23999/j.dtomp.2022.2.1

(c) 2022 OMF Publishing, LLC. This is an open access article under the CC BY license (http://creativecommons.org/licenses/by-nc/4.0/). 
They offer a chance to reflect not only on remarkable achievements but also on collaborations, networking, and friendships that have helped us shape the past five years of our journal. Historical milestones in this journey provide a reason to celebrate and include:

- Launch of a section "Images" (2019) with an appointment of Dr. Mosquera as a founding section editor. For this section the extra short type articles are prepared and submitted similarly to the articles in the section "Images in Clinical Medicine" of the New England Journal of Medicine.

- Gradual transition from a quarterly to monthly publication (in a 2019-2020).

- Launch of a new media platform (March 2020) with the support of smartphone and tablet views.

- Integration of the article in press option at the journal's platform. In other publishers this option is also known as article in advance, early view, etc.

- Launch of a section "Business" (2021) with an appointment of Dr. Nagorniak as a founding section editor.

- Covid-19 response: our journal during last two years is constantly publishing the articles focused on pandemic and its influence on OMS. Moreover, we support an article publishing charge waiver for the submitted and accepted manuscripts which are related with Covid-19 topic.

- Publishing video articles with a launch of YouTube channel (Videos of JDTOMP).

- Publication of articles from almost 15 countries from 4 different continents proved the global vision of the journal's board. Among authors affiliation counties are: Belarus, Brazil, Chile, Colombia, France, Georgia, Greece, India, Italy, Mexico, Slovak Republic, Spain, Ukraine, United Arab Emirates, and the United States of America.

- Transition to digital-only fully open access publication from January 1, 2022.

- Launch of a resident ambassador position in the editorial board from January 1, 2022. Dr. Le's appointment for this founding position. ${ }^{2}$

- The articles of 13 different categories are already published: (1) editorials/guest editorials/ post scriptum editorials, (2) images, (3) case reports/case series, (4) original articles, (5) review articles, (6) discussions, (7) paper scans (synonyms: review of articles, literature scans), (8) book scans (synonym: book reviews), (9) letters to the editor (synonym: letters), (10) responses, (11) viewpoints, (12) obituaries, and (13) review of events.

- The articles became cited in journals covered by Scopus database and publications with a high Impact Factor (like Atlas of the Oral and Maxillofacial Surgery Clinics, European Journal of Plastic Surgery, Oral and Maxillofacial Surgery Clinics of North America [2020 Impact Factor $=2.802]$, Oral Diseases [2020 Impact Factor $=3.511]$, The Cleft Palate-Craniofacial Journal [2020 Impact Factor $=1.433$ ], etc.). ${ }^{3-}$

- As February 1, 2022 the editorial board brought together 28 professionals from 13 countries.

- Launch of the social media pages (Instagram [@ dt_journal], Facebook [Journal of Diagnostics and Treatment of Oral and Maxillofacial Pathology], and Twitter [@DTJournal1]) reaching more than 2,000 followers. Such steps helped the editorial board to find readers and partners around the globe in a completely unpredictable way and sometimes without even in-person offline communication and negotiations.

- Social media pages proved it effectiveness in the DT Journal's visibility. The authors even found our journal for the article submission via the conference Hashtag \#icoms2017 in the Instagram and after that peer-reviewed process were accepted. ${ }^{8}$

However, milestones always cause me to deeply reflect not on what has been accomplished but instead on what else needs to be completed and improved. This should be the challenge of a responsible medical journal. Sparing time for scholarly or research activity requires significant commitment and motivation. Still, my mind will continue to focus on changes that we must make to ensure that we are correctly informing and engaging the clinical and academic OMS community in a holistic approach. This is a testament to our journal's vision, leadership, and teamwork. The DT Journal has strong momentum, effective leadership, and a proven editorial team of experts committed to the continued growth and development of the journal 
through activities to increase engagement with OMS clinicians and scientists worldwide. In partnership with our international contributors, board, reviewers, and society colleagues, we look to the future with confidence on disseminating the rapid progress in OMS by making high-quality material systematically available through one central source.

The DT Journal will continue to publish papers that highlight the significant clinical advances in OMS and promote emerging laboratory research and broad-spectrum educational topics. We will continue to improve our web presence by regularly updating our website to make it readable and valuable to practicing oral and maxillofacial surgeons, trainees, and investigators. Our readers will have access to medically relevant content through this advanced structural model. Still, they will have a chance to experience a powerful international networking platform that will significantly enhance the value and visibility of both scientists and the journal itself. These innovations will increase the global reach, overall quality, and impact of the research, discovery, and education missions of the DT Journal to its constituents and will sustain and enhance its general excellence by offering a 5-Star experience to our readers. It is imperative to continue pursuing these and other innovative approaches to follow the core missions of the DT Journal and ensure that it will remain a respected voice in research and academic OMS.

Today, we live and function within a highly interconnected world, both personally and professionally. The same principle applies to medical journals like DT Journal, which will need to play evolving roles in this new landscape. It will provide a bright window into the changing functions of medical journals and the medical profession because journals don't simply disseminate new knowledge about medical theory and practice. They also define the scope of medical concerns and articulate norms for physicians' professional and social roles. And a rededicated, respected, worldwide community of oral and maxillofacial surgeons can provide this leadership. Such an achievement would offer a fitting complement to our remarkable scientific endeavors.

Our journal will be actively involved in the crucially needed therapy for the fragmented humanity with both a general and specific reorientation of scientific priorities toward the advancement of all humankind as a composite being, rather than toward the progress of our individual lives. The DT Journal's mediation between biomedical science and the social context of OMS health care demonstrates another role of medical journals and a paradigm shift: their definition of the OMS profession as a social and moral community.

Navigating many obstacles, medical journals have persisted by adapting to changing environments and embracing new opportunities. Journals must continue to manage not just the shifting landscape of the production and publishing of medical knowledge but also the broader currents of their social, economic, and political contexts, and I can confidently affirm that this vision will become a reality in DT Journal.

Today, DT Journal reflects a view that OMS science and its applications are fundamentally tied to optimal patient care and public health.

Please, join me and celebrate the Fifth Anniversary of DT Journal on this exciting global journey.

\section{REFERENCES (8)}

1. Tymofieiev OO, Fesenko II, Kilipiris EG. Evolving: becoming a printable digital-only journal from January 2022. J Diagn Treat Oral Maxillofac Pathol 2021;5(12):137-8.

https://doi.org/10.23999/j.dtomp.2021.12.2

2. Le JM. In response to the editorial "Meet the founding resident ambassador: John M. Le, DDS, MD." J Diagn Treat Oral Maxillofac Pathol 2022;6(1):6. https://doi.org/10.23999/j.dtomp.2022.1.3

3. Weyh A, Quimby A, Salman O. Zygomatic implants in avulsive and ablative defects. Atlas Oral Maxillofac Surg Clin North Am 2021;29(2):271-6. https://doi.org/10.1016/j.cxom.2021.05.001

4. Bishop RA, Woerner JE, Stavropoulos F. Effects of the COVID-19 pandemic on the professional career of women in OMS. Oral Maxillofac Surg Clin North Am 2021;33(4):475-80.

https://doi.org/10.1016/j.coms.2021.06.002

5. Manfredi M, Gessaroli M, Melis M, Massarelli. A novel patient positioning technique during raising peroneal system free flaps. Eur J Plast Surg 2022;45(1). https://doi.org/10.1007/s00238-021-01906-1

6. Fusconi, M, Meliante, PG, Pagliuca, G, Greco A, de Vincentiis M, Polimeni A, Musy I, Candelori F, Gallo A. Interpretation of the mucous plug through sialendoscopy. Oral Dis 2021;00:1-6.

https://doi.org/10.1111/odi.13796

7. Kilipiris EG, Horn F, Kolnikova M, Ochoa JV, Matuskova O, Jelovac D, Stebel A. Parental satisfaction from telemedicine in the follow-up of children operated for craniosynostosis during COVID-19 pandemic. Cleft Palate Craniofac J 2022:10556656221074214. 
https://doi.org/10.1177/10556656221074214

8. Monteiro JL, Fesenko II. Every hashtag matters: an importance of that Instagram tool in a life of the peer-reviewed journal. J Diagn Treat Oral Maxillofac Pathol 2019;3(5):A11.

https://doi.org/10.23999/j.dtomp.2019.5.1 